\title{
Communication \\ Electrochemical Molecular Conversion of $\alpha$-Keto Acid to Amino Acid at a Low Overpotential Using a Nanoporous Gold Catalyst
}

\author{
Yasuhiro Mie *(D), Shizuka Katagai and Chitose Mikami \\ Bioproduction Research Institute, National Institute of Advanced Industrial Science and Technology (AIST), \\ 2-17-2-1, Tsukisamu-higashi, Toyohira, Sapporo 062-8517, Japan; s.katagai@aist.go.jp (S.K.); \\ mikami-c@aist.go.jp (C.M.) \\ * Correspondence: yasuhiro.mie@aist.go.jp; Tel.: +81-11-857-8521
}

Citation: Mie, Y.; Katagai, S.; Mikami, C. Electrochemical Molecular Conversion of $\alpha$-Keto Acid to Amino Acid at a Low Overpotential Using a Nanoporous Gold Catalyst. Int. J. Mol. Sci. 2021, 22, 9442. https://doi.org/10.3390/ ijms22179442

Academic Editor: Raphaël Schneider

Received: 31 July 2021

Accepted: 26 August 2021

Published: 31 August 2021

Publisher's Note: MDPI stays neutral with regard to jurisdictional claims in published maps and institutional affiliations.

Copyright: (c) 2021 by the authors. Licensee MDPI, Basel, Switzerland. This article is an open access article distributed under the terms and conditions of the Creative Commons Attribution (CC BY) license (https:/ / creativecommons.org/licenses/by/ $4.0 /)$.

\begin{abstract}
A nanoporous gold (NPG) electrode prepared through a facile anodization technique was employed in the electrochemical reductive amination of biomass-derivable $\alpha$-keto acids in the presence of a nitrogen source to produce the corresponding amino acids. NPG showed a clear reductive current in the presence of $\alpha$-keto acid and $\mathrm{NH}_{2} \mathrm{OH}$, and the electrolysis experiments confirmed the production of L-amino acid. A reductive voltammetric signal at the NPG electrode appeared at a more positive potential by $0.18-0.79 \mathrm{~V}$, compared with those at the planar-gold electrode without anodization and other previously reported electrode systems, indicating the high activity of the prepared nanostructure for the electrochemical reaction. Maximum Faradaic efficiencies (FEs) of 74-93\% in the reductive molecular conversion to amino acids of Ala, Asp, Glu, Gly, and Leu were obtained under the optimized conditions. The FE values were strongly dependent on the applied potential in the electrolysis, suggesting that the hydrogen evolution reaction at the electrode surface was more significant as the applied potential became more negative. The effect of potential at the NPG was lower than that at the planar-gold electrode. These results indicate that nanostructurization decreases the overpotential for the electrochemical reductive amination, resulting in high FE.
\end{abstract}

Keywords: biomass-derivable; amino acid; electrosynthesis; nanoporous gold; anodization

\section{Introduction}

As the demand for a sustainable society increases, efforts have been made to develop environmentally friendly methods for chemical production [1]. The electrochemical molecular conversion of redox-active species is one of the useful strategies to synthesize organic molecules in addition to sensor and energy conversion technologies as it can be conducted with electricity from renewable energy sources [2-4]. Furthermore, as the electrochemical system can be easily miniaturized, it has advantages, especially for the distributed on-site production of high-value chemicals in on-demand needs [1].

In electrochemical methods, an electrode works as a catalyst and an electron server/receiver. Therefore, in addition to the nature of the electrode materials, its surface structure is a key factor that determines the catalytic activity. Owing to the growth of nanotechnological methods, electrodes composed of nanomaterials and the nanostructurization of electrode surfaces have been developed [5-7]. Now, it is well-recognized that the nanoarchitecture of electrodes significantly enhances the electrocatalytic activity, and one of the reasons is the abundant low-coordinated surface atoms at the steps/kinks [8-10]. Among many types of nanostructured electrodes, nanoporous metals have been attracted in many fields owing to their large surface area [11,12]. Nanoporous gold (NPG) is promising in electrochemical applications of catalysis and sensing, owing to its advantages, such as high conductivity, catalytic activity, chemical inertness, physical stability, reusability, and facile surface modification. Several efficient electrocatalytic reactions using NPG, including the reduction of $\mathrm{CO}_{2}$ and $\mathrm{H}_{2} \mathrm{O}_{2}$, oxidation of alcohol, glucose, $\mathrm{CO}$, and aromatic compounds, and hydrogenation reactions of alkynes and alkenes, have been reported [13-20]. 
To date, NPG has been mostly prepared by the selective etching of a less noble component in gold-containing metal alloys. Its catalytic properties for redox-active molecules have been extensively studied, and the enhanced activity has been discussed [21-23]. Recently, a more facile and time-saving method, where NPG is fabricated by simply anodizing conventional planar (commercially available) gold electrodes, has been reported [24] and developed [25-29]. Anodization in a solution containing a high (0.5-2 $\mathrm{M}) \mathrm{Cl}^{-}$concentration is a rapid (within $2 \mathrm{~min}$ ) strategy for producing NPG composed of ligaments and pores $[24,25]$, which are similar to those prepared using the conventional dealloying method described above. NPG with thinner ligaments was also prepared by anodization in a solution of lower $\mathrm{Cl}^{-}$concentrations [28,29]. An enhanced electrocatalytic activity of anodized NPGs was reported for such reactions as $\mathrm{O}_{2}$ reduction, $\mathrm{CO}_{2}$ reduction, and monosaccharide oxidation [30-32], revealing the potency of NPGs.

Currently, $\alpha$-keto acid derivatives can be produced from lignocellulosic biomass, which can be a non-food-competing chemical feedstock [33-35]. Hence, the electrochemical reductive amination of keto acids to produce the corresponding amino acids is desired as an environmentally friendly method as amino acids are useful materials in the industry, and the current production system with a microbial fermentation process or chemical synthesis has several challenges, such as low efficiency for some amino acids, high energy consumption, and the use of hazardous chemicals [33,36-38]. Unfortunately, studies on the electrochemical conversion of $\alpha$-keto acids to amino acids are very limited, and previous reports employed $\mathrm{Hg}, \mathrm{Pd}, \mathrm{Pt}$, and graphite electrodes [39-41]. Recently, Fukushima et al. reported the electrochemical production of seven amino acids from the corresponding $\alpha$-keto acids using the anatase- $\mathrm{TiO}_{2}$-based electrode with an extremely high Faradaic efficiency (FE) of $\sim 99 \%$ at $0{ }^{\circ} \mathrm{C}$ [33]. However, gold materials have not been used to investigate the aforementioned electrochemical conversion, and the effect of nanostructures on the reaction is unknown.

In this study, the nanostructurization of gold electrodes significantly improved the electrochemical reductive amination of $\alpha$-keto acids to produce the corresponding L-amino acids (Figure 1). We demonstrated that NPG enables the amino acid production at a lower overpotential, which separates the reductive amination reaction from the competing hydrogen evolution reaction (HER) at the gold surface, resulting in a high FE of $\sim 93 \%$ for the electrochemical molecular conversion.

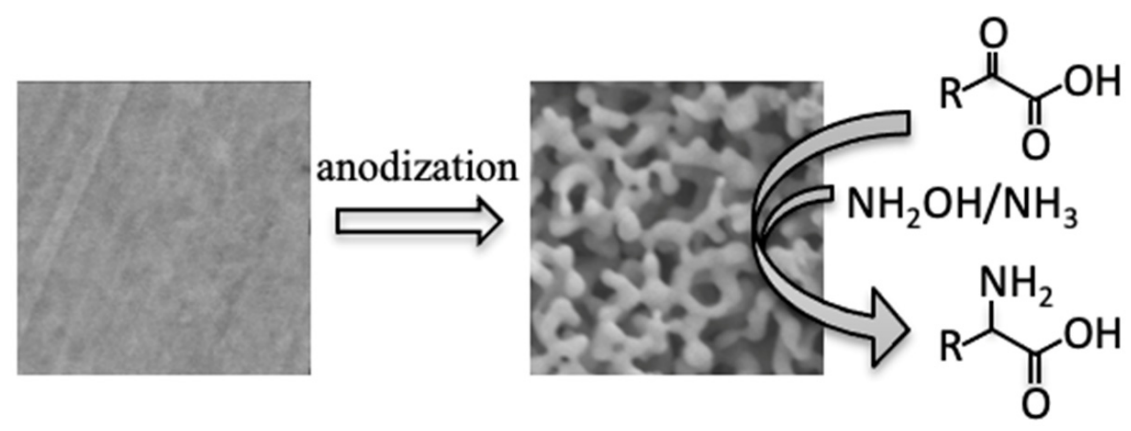

Figure 1. Schematic representation of electrochemical molecular conversion: nanostructurization for a commercially available planar-gold electrode surface and the electrochemical reductive amination of $\alpha$-keto acid in the presence of a nitrogen source to produce L-amino acid.

\section{Results and Discussion}

2.1. Electrochemical Reduction of Ketoglutaric Acid at NPG and Conventional (Planar) Gold Electrodes in the Presence of a Nitrogen Source

First, we targeted $\alpha$-ketoglutaric acid (2-oxoglutaric acid) and conducted voltammetry and electrolysis to investigate whether gold materials enable the electrochemical conversion of the $\alpha$-keto acid to the corresponding amino acid (L-glutamic acid) in the presence of a nitrogen source. The morphologies of the gold electrodes, i.e., the conventional planar (without anodization) gold and anodized NPG, are shown in Figure 2a,b. The anodization 
process yielded a nanoporous structure composed of $\sim 50 \mathrm{~nm}$ sized ligaments on the material, consistent with previous reports [28,29]. NPG with a roughness factor $\left(R_{\mathrm{f}}\right)$ of about 5 (electrode surface area $=0.35 \pm 0.10 \mathrm{~cm}^{-2}$ ) was used herein as higher $R_{\mathrm{f}}$ values result in deeper nanoporous layers in the NPG structure, which hinders the diffusion of the target molecule deep inside of the porous structure [29].

(a)

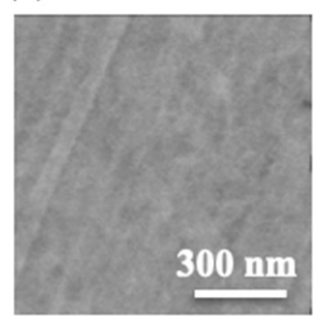

(b)

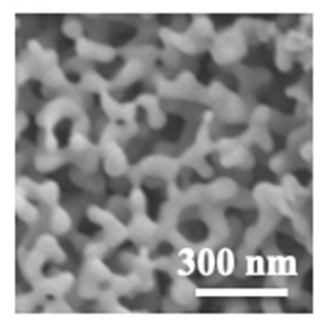

(c) 0

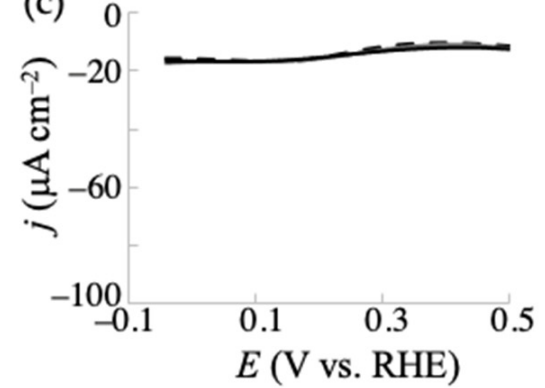

(d)

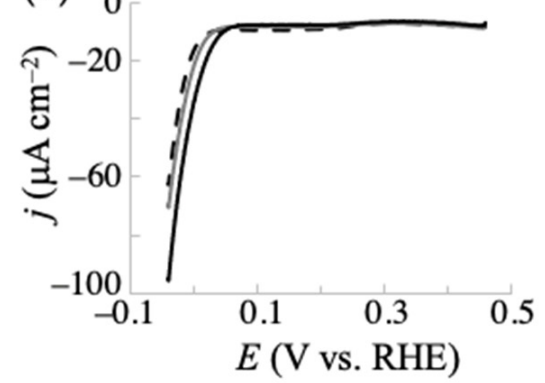

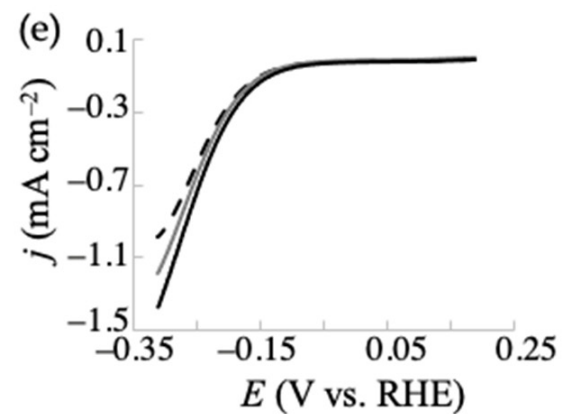

(f)

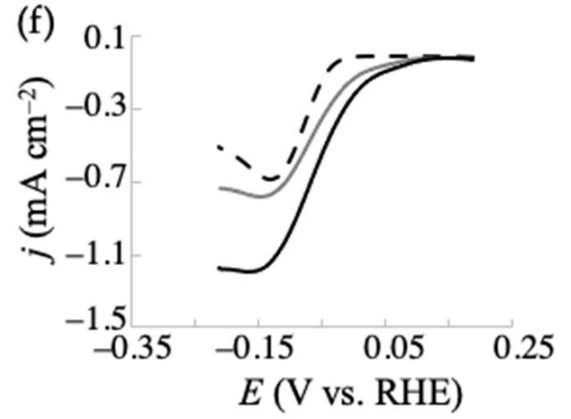

Figure 2. Surface morphologies of (a) planar (nonanodized) gold and (b) anodized NPG electrodes observed by SEM. (c-f) Cyclic voltammograms obtained at the electrodes. Voltammograms for $25 \mathrm{mM}$ (gray line) and $50 \mathrm{mM}$ (black line) of $\alpha$-ketoglutaric acid measured in (c,d) $1.5 \mathrm{M}$ of $\mathrm{NH}_{3} / \mathrm{NH}_{4} \mathrm{Cl}$ solution $(\mathrm{pH} 10)$ and $(\mathbf{e}, \mathbf{f}) 0.15 \mathrm{M}$ of $\mathrm{NaCl}$ solution containing $50 \mathrm{mM}$ of $\mathrm{NH}_{2} \mathrm{OH}$ (pH 1.6) at (c,e) planar-gold and (d,f) NPG electrodes. Dashed lines indicate voltammograms recorded without $\alpha$-ketoglutaric acid and $\mathrm{NH}_{2} \mathrm{OH}$.

According to the previous studies [33,39-41], $\mathrm{NH}_{3}$ and $\mathrm{NH}_{2} \mathrm{OH}$ were used as nitrogen sources in the electrochemical reductive amination at gold electrodes. The former and the latter were examined in $1.5 \mathrm{M}$ of $\mathrm{NH}_{3} / \mathrm{NH}_{4} \mathrm{Cl}$ buffer ( $\left.\mathrm{pH} 10\right)$ and in $0.15 \mathrm{M}$ of $\mathrm{NaCl}$ solution containing $50 \mathrm{mM}$ of $\mathrm{NH}_{2} \mathrm{OH}$ ( $\mathrm{pH}$ was adjusted to 1.6), respectively. The linear sweep voltammograms obtained at the planar-gold and NPG electrodes in the presence and absence of $\alpha$-ketoglutaric acid at a potential scan rate of $5 \mathrm{mV} \mathrm{s}^{-1}$ are shown in Figure 2c-f. When $\mathrm{NH}_{3}$ was used as the nitrogen source, no significant reductive current was observed at the planar-gold electrode (Figure 2c), and a relatively small increase in current (compared with the previous study [33] and undermentioned $\mathrm{NH}_{2} \mathrm{OH}$ case) at the NPG electrode starting at around $0.03 \mathrm{~V}$ (Figure 2d) upon the addition of $\alpha$-ketoglutaric acid was observed. The lower activity compared with the below $\mathrm{NH}_{2} \mathrm{OH}$ case agrees with the previous report [33], and the significantly smaller current changes herein indicate that the gold material was not effective for the reductive amination of $\alpha$-ketoglutaric acid with $\mathrm{NH}_{3}$ ( $\mathrm{pH} 10$ ) as the nitrogen source. On the other hand, when $\mathrm{NH}_{2} \mathrm{OH}$ was used, a significant increase in the reductive current was observed in the presence of $\alpha$-ketoglutaric acid at both planar-gold and NPG electrodes (Figure 2e,f), especially at the latter. The current increased with the concentration of $\alpha$-ketoglutaric acid, indicating the electrochemical reductive reaction of the substance. Importantly, the NPG surface exhibited the reductive current starting at around $0.1 \mathrm{~V}$, which was a much more positive potential by $0.18-0.30 \mathrm{~V}$ compared with those at the planar-gold (Figure 2e) and previously reported $\mathrm{TiO}_{2}$ electrodes (with a scan rate of $10 \mathrm{mV} \mathrm{s}^{-1}$ and $\mathrm{pH} 0.53$ ) [33] with $\mathrm{NH}_{2} \mathrm{OH}$ as the nitrogen source. It was also much more positive by $\sim 0.79 \mathrm{~V}$ compared with those obtained at $\mathrm{Hg}, \mathrm{Pt}, \mathrm{Pd}$, and graphite electrodes with $\mathrm{NH}_{3}$ as the nitrogen source [39-41]. These indicate that the 
present anodized NPG could be a useful catalyst for the electrochemical production of L-glutamic acid from $\alpha$-ketoglutaric acid in the presence of $\mathrm{NH}_{2} \mathrm{OH}$.

To confirm the formation of L-glutamic acid in the above electrochemical reduction reaction, electrolysis experiments of a $50 \mathrm{mM} \alpha$-ketoglutaric acid solution were conducted. The electrolysis time was set for $120 \mathrm{~min}$ and $30 \mathrm{~min}$ for the planar-gold and NPG electrodes, respectively, in consideration of the difference in each electrode surface area. The electrolyzed solutions were analyzed by high-performance liquid chromatography (HPLC) with a phenyl isothiocyanate prelabeling strategy and enzymatic L-glutamic acid assay with a redox dye system of the commercially available kit. Applied potentials of 0.02 and $-0.04 \mathrm{~V}$ were used for the electrolysis with $\mathrm{NH}_{3}$ and $50 \mathrm{mM}$ of $\alpha$-ketoglutaric acid at the NPG and planar-gold electrodes, respectively, whereas -0.01 and $-0.11 \mathrm{~V}$ were employed in the case of $\mathrm{NH}_{2} \mathrm{OH}$ at NPG and planar-gold electrodes, respectively. Figure 3a shows the typical chromatogram recorded for the electrolyzed solution of $50 \mathrm{mM}$ of $\alpha$-ketoglutaric acid and $\mathrm{NH}_{2} \mathrm{OH}$ using NPG for $30 \mathrm{~min}$ and at an applied potential of $-0.01 \mathrm{~V}$. Compared with the chromatogram of the standard L-amino acid solution (Figure 3b), the formation of L-glutamic acid was evident, indicating successful electrochemical reductive amination [33]. The enzymatic assay also indicated the production of a similar amount of L-glutamic acid (not shown here). To evaluate the efficiency of the present electrochemical conversion, the FE was evaluated using the charge passed through during the electrolysis and the amount of produced L-glutamic acid. Referring to the previous electrochemical study of $\alpha$-keto acids in the presence of a nitrogen source, we assumed that the conversion of $\alpha$-keto acids to L-amino acids proceeds with two- and four-electron reduction through imine and oxime as a nitrogenated intermediate in the presence of $\mathrm{NH}_{3}$ and $\mathrm{NH}_{2} \mathrm{OH}$, respectively [33]. Figure $3 \mathrm{c}$, d show the averaged $\mathrm{FE}$ values calculated for the reduction in the solution containing $\mathrm{NH}_{3}$ and $\mathrm{NH}_{2} \mathrm{OH}$ at both the planar-gold and $\mathrm{NPG}$ electrodes. In the case of $\mathrm{NH}_{3}$, no L-glutamic acid was produced at the planar-gold electrode, and a very small amount was produced at the NPG electrode, resulting in an FE of 5\%. This is reasonably accepted in consideration of the voltammetric responses described above. Again, a lower activity of the gold electrodes for the electrochemical reductive amination of $\alpha$-keto acid in $\mathrm{NH}_{3} / \mathrm{NH}_{4} \mathrm{Cl}$ solution was observed. On the other hand, as for the $\mathrm{NH}_{2} \mathrm{OH}$ case, $\mathrm{FE}$ values of $16 \%$ and $89 \%$ were obtained at the planar-gold and NPG electrodes, respectively. The efficiency at the NPG electrode was much higher than that at the planar-gold, and the catalytic activity of the gold electrode was significantly improved by nanostructurization (facile anodization treatment). Combined with the voltammetric results, where the reductive conversion was observed with a lower overpotential at the NPG electrode, we conclude that the NPG surface is an effective catalyst for converting biomass-derivable $\alpha$-keto acid with $\mathrm{NH}_{2} \mathrm{OH}$ as a nitrogen source to the corresponding L-amino acid with a high FE and low overpotential. The electrochemical sensing applications of NPG, particularly that prepared using a dealloying method, have been studied extensively [42-44]. The results showed that the nanoporous structure enhances the electrochemical signals and lowers the overpotential for redox reactions. The present anodized NPG has a similar shape to that of the dealloyed NPG. Therefore, the higher current at lower overpotential in the present $\alpha$-keto acid reduction agrees with the aforementioned reports. 

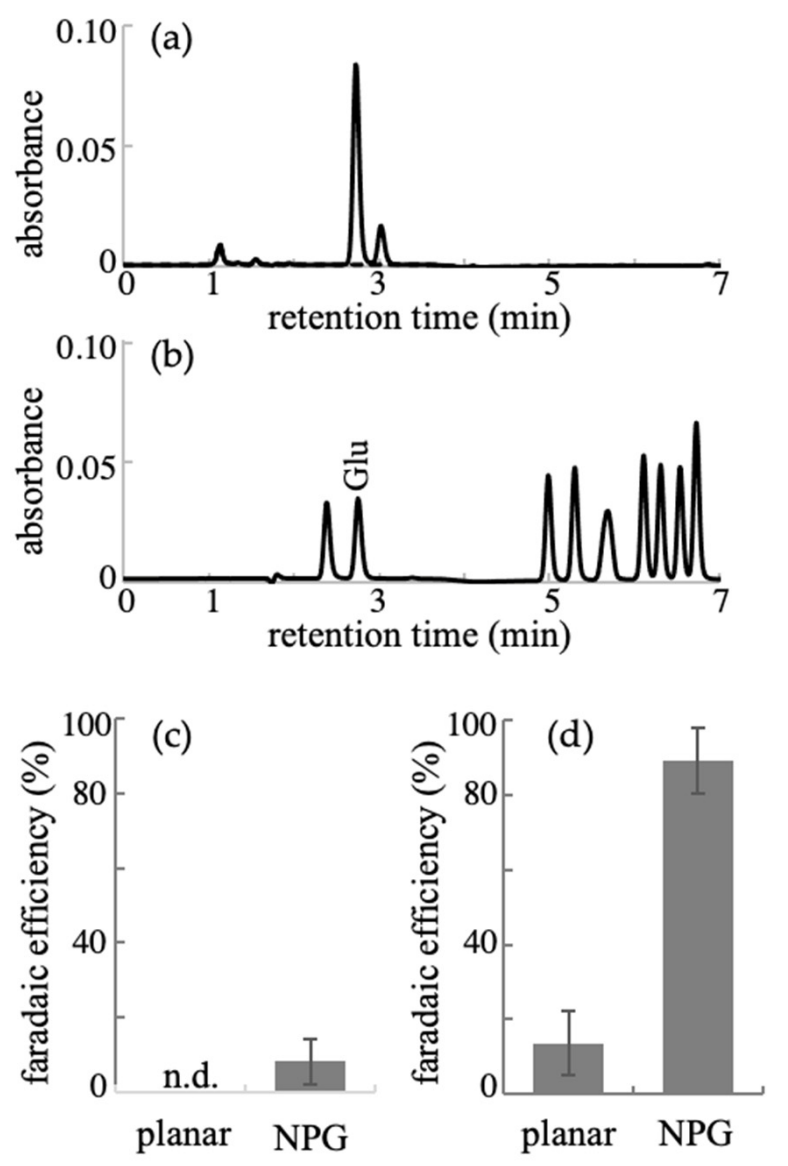

Figure 3. Typical HPLC chromatograms of (a) electrolyzed solution for $50 \mathrm{mM}$ of $\alpha$-ketoglutaric acid in the presence of $50 \mathrm{mM}$ of $\mathrm{NH}_{2} \mathrm{OH}$ using anodized NPG electrode for $30 \mathrm{~min}$ and (b) standard solutions containing $1 \mathrm{nmol}$ of L-amino acids. The dotted line in (a) indicates the chromatogram of the solution before electrolysis. Faradaic efficiency (FE) for electrochemical production of L-glutamic acid at planar-gold and NPG electrodes in the presence of (c) $\mathrm{NH}_{3}$ and (d) $\mathrm{NH}_{2} \mathrm{OH}$ as nitrogen sources. EF values are represented as mean $\pm \mathrm{SD}$ ( $n=3$ independent experiments). "n.d." means not detected.

\subsection{Effect of Applied Potential on the Electrochemical Production of L-Glutamic Acid}

The effective catalytic properties of the anodized NPG for the electrochemical reductive amination of $\alpha$-ketoglutaric acid using $\mathrm{NH}_{2} \mathrm{OH}$ as a nitrogen source were demonstrated as described above. The applied potential in the electrochemical molecular conversion is one of the key factors affecting reaction efficiency. We examined the effect of applied potential on the electrolysis of $50 \mathrm{mM}$ of $\alpha$-ketoglutaric acid with an equivalent amount of $\mathrm{NH}_{2} \mathrm{OH}$ using both planar-gold and NPG electrodes for $120 \mathrm{~min}$ and $30 \mathrm{~min}$, respectively. The optimized concentration of $\alpha$-ketoglutaric acid of $50 \mathrm{mM}$ (Figure S1) was selected. From the linear sweep voltammograms (Figure 2e,f), onset potentials of approximately -0.06 and $0.12 \mathrm{~V}$ for the reductive current for $\alpha$-ketoglutaric acid were estimated at the planar-gold and NPG electrodes, respectively. Hence, applied potentials more negative than these values for the electrolysis were set. As shown in Figure 4, the FE for the electrochemical production of L-glutamic acid from $\alpha$-ketoglutaric acid was strongly dependent on the applied potential in the electrolysis at both the planar-gold and NPG electrodes. For the NPG electrode, as the applied potentials became negative, the FE gradually decreased. The FE for the production of L-glutamic acid obtained at $-0.21 \mathrm{~V}$ was about $40 \%$ of that observed at $0.04 \mathrm{~V}$. A similar tendency was observed at the planar-gold electrode, and the effect of potential was higher than that at the NPG electrode. At $-0.310 \mathrm{~V}$, the FE was less than $10 \%$ compared with that at $-0.06 \mathrm{~V}$. The NPG electrode exhibited the highest 
averaged FE of $\sim 90 \%$ at potentials more positive than $-0.01 \mathrm{~V}$, which is close to the highest value $(96.7 \%)$ in a previous study at a $\mathrm{TiO}_{2}$-based electrode with an applied potential of $-0.5 \mathrm{~V}$. On the other hand, the maximum value obtained at the planar-gold electrode was $16 \%$ at a potential of $-0.06 \mathrm{~V}$. These results indicate that the anodized nanostructure considerably improves the electrocatalytic activity for the conversion of $\alpha$-ketoglutaric acid to the glutamic acid in the presence of a nitrogen source and can be an effective catalyst for the reaction.
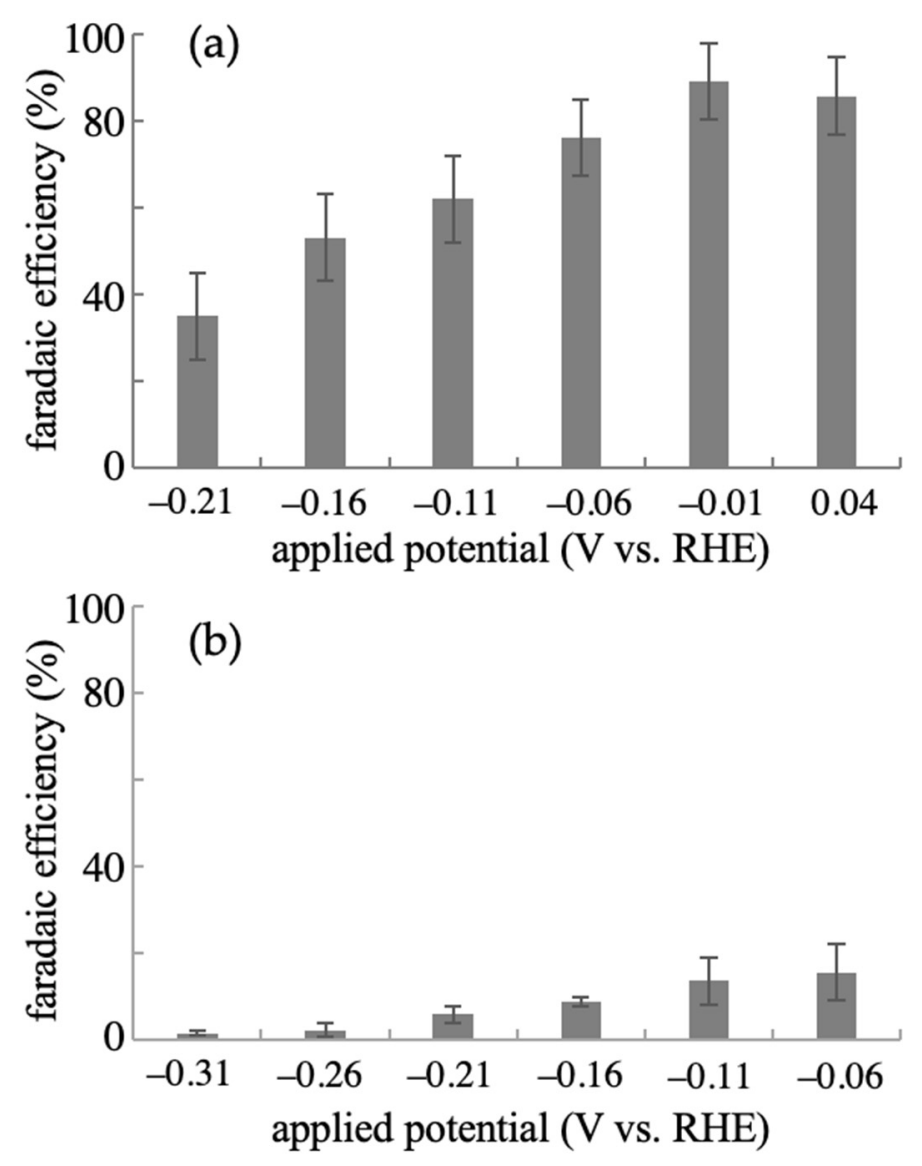

Figure 4. Relationship between FE of L-glutamic acid production and applied potentials for the electrolytic reaction of $50 \mathrm{mM}$ of $\alpha$-ketoglutaric acid in the presence of $50 \mathrm{mM}$ of $\mathrm{NH}_{2} \mathrm{OH}$ using (a) NPG and (b) planar-gold electrodes. FE values are presented as mean \pm SD $(n=3$ independent experiments).

Considering the $\mathrm{pH}$ of 1.6 used for the electrochemical conversion, the HER should be considered at gold material electrodes, especially for the nanostructured ones [42-44]. HERs on metallic-based electrodes compete with and inhibit the target/desired reactions, such as the electrochemical reduction of water-soluble carboxylic acids [45]. As shown in Figure 2e,f (dotted lines), the planar-gold and NPG electrodes exhibited a significant reductive current at potentials more negative than -0.11 and $-0.01 \mathrm{~V}$, respectively, in the absence of $\mathrm{NH}_{2} \mathrm{OH}$ and $\alpha$-ketoglutaric acid, indicating the occurrence of HER, which decreases the FE of the electrosynthesis of L-glutamic acid under these potentials. The reductive current signal of HER (dashed line in Figure 2e,f) against the total reductive signal (solid line in Figure 2e,f) at the planar-gold electrode was larger than that at the NPG electrode. These voltammetric features are consistent with the effect of the applied potential on the FE in L-glutamic acid production. These results suggest that nanostructurization of the surface of the planargold electrode by the facile anodization process improves the activity for the reduction of $\alpha$-keto glutaric acid than for HER. Hence, the two electrochemical reductive reactions could be separated in the electrolysis experiments at appropriate applied potentials with 
the NPG electrode, resulting in a high FE. A previous study reported that a conventional planar gold and NPG electrode have different compositions of surface crystallographic orientations [29]. Therefore, the orientation of NPG could favor an interaction with the reactant/intermediate for the reduction of $\alpha$-keto acids compared to that of the HER. The details of this phenomenon are under investigation.

\subsection{Reusability and Generality}

To further investigate the efficacy of the NPG electrode for the electrochemical synthesis of amino acids from $\alpha$-keto acids, reusability tests for the electrode were conducted. Figure 5 shows the $\mathrm{FE}$ values evaluated from five sequential reductive electrolysis reactions for $\alpha$-ketoglutaric acid in the presence of the corresponding amount of $\mathrm{NH}_{2} \mathrm{OH}$ under a fixed condition using a single NPG electrode. The NPG electrode showed almost constant FE values, indicating less deterioration of the activity of the electrode surface during the experiments. This was also supported by the similar surface morphology of NPG before and after the electrolysis experiments (Figure S2).

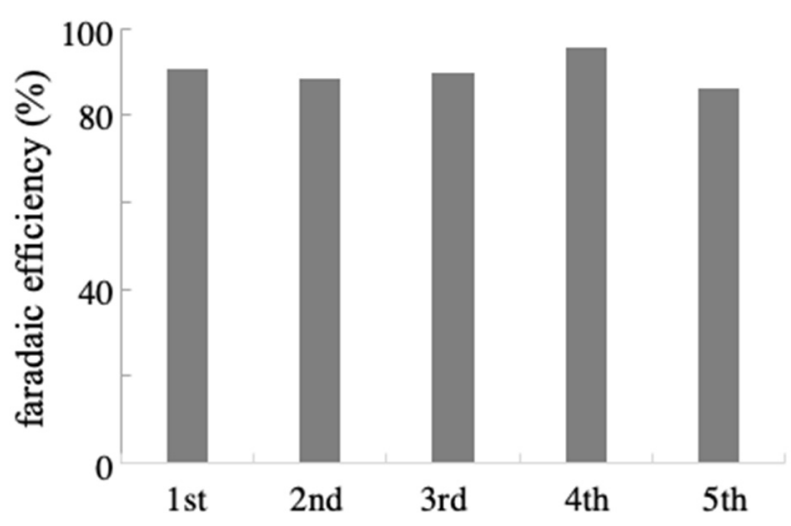

Figure 5. FE for L-glutamic acid production obtained at a single NPG electrode from five sequential experiments. Electrolysis was conducted on $50 \mathrm{mM}$ of $\alpha$-ketoglutaric acid in the presence of $\mathrm{NH}_{2} \mathrm{OH}$ at $-0.01 \mathrm{~V}$ for $30 \mathrm{~min}$.

Finally, we examined if the NPG can be used for the conversion of other $\alpha$-keto acids to produce the corresponding L-amino acids. Fukushima et al. [33] reported that alanine, aspartic acid, glutamic acid, glycine, and leucine were electrosynthesized with a high FE of $91-99 \%$ from the corresponding $\alpha$-keto acids, i.e., pyruvic, oxaloacetic, $\alpha$-ketoglutaric, glyoxylic, and 4-methyl-2-oxovaleric acid, respectively, using an anatase $\mathrm{TiO}_{2}$ electrode with an applied potential of $-0.5 \mathrm{~V}$. Herein, the $\alpha$-keto acids were converted in the presence of $\mathrm{NH}_{2} \mathrm{OH}$ using the anodized NPG electrode with an applied potential of $-0.01 \mathrm{~V}$, which was sufficient to reduce all the $\alpha$-keto acids tested in this study. HPLC analysis and an enzymatic assay of each electrolyzed solution revealed the successful production of the corresponding L-amino acids. The calculated FEs are depicted in Figure 6. All amino acids tested were produced with an FE of 74-93\%. Except for Gly, whose average FE was significantly small ( $74 \%$ ) (the reason is yet to be clarified), the FE for the production of other amino acids (89-93\%) was close to the highest values in previous reports [33]. Hence, the anodized NPG electrode has high potency for the electrochemical production of L-amino acids from the biomass-derivable $\alpha$-keto acids, and the nanostructurization of gold materials would be effective for developing catalytic electrodes for electrochemical molecular conversions. 


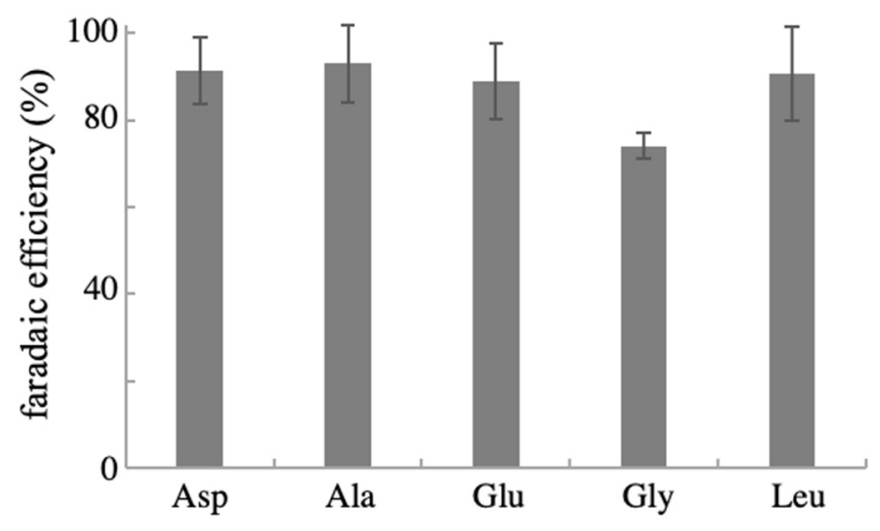

Figure 6. FE for the electrochemical conversion of $\alpha$-keto acids with $\mathrm{NH}_{2} \mathrm{OH}$ to the corresponding amino acids using an NPG electrode. A solution containing $50 \mathrm{mM}$ of $\alpha$-keto acid and $\mathrm{NH}_{2} \mathrm{OH}$ was electrolyzed at $-0.01 \mathrm{~V}$ for $30 \mathrm{~min}$. The FE values are presented as mean $\pm \mathrm{SD}(\mathrm{n}=4$ independent experiments).

\section{Materials and Methods}

\subsection{Materials}

Oxaloacetic acid, $\alpha$-ketoglutaric (2-oxoglutaric) acid, ammonia solution, hydroxyammonium sulfate, amino acids standard solution (Type $\mathrm{H}$ ), phenyl isothiocyanate (PITC), PTC-amino acid mobile phase solutions A and B, and a Wakosil-PTC column were purchased from FUJIFILM Wako Pure Chemical Corporation (Osaka, Japan). Pyruvic and glyoxylic acids were purchased from Tokyo Chemical Industry Co., Ltd. (Tokyo, Japan). 4-Metyl-2-oxovaleric acid and an L-amino acid quantification kit were purchased from Sigma-Aldrich Co. LLC (St. Louis, MO, USA). An L-glutamate kit YAMASA NEO was purchased from Yamasa Corporation (Choshi, Japan). Electrodes, including gold disks $(\varnothing=3 \mathrm{~mm})$, $\mathrm{Pt}$ coils, and $\mathrm{Ag}|\mathrm{AgCl}|$ sat. $\mathrm{KCl}$, were purchased from BAS Inc., (Tokyo, Japan).

\subsection{Electrode Preparation}

A gold disk electrode was polished with 1 and $0.125 \mu \mathrm{m}$ of diamond slurries, followed by $0.05 \mu \mathrm{m}$ of alumina slurry, and electrochemically cleaned in a $0.5 \mathrm{M} \mathrm{H}_{2} \mathrm{SO}_{4}$ solution. To prepare the NPG electrode, first, the cleaned gold disk was immersed in a $0.5 \mathrm{M}$ $\mathrm{HCl}$ solution, and linear sweep voltammetry was conducted to evaluate the passivation potential, where the gold electrode surface was passivated by the formation of an oxide layer with a sudden current drop after the flow of the gold dissolution current [24,25,29]. Then, the constant potential for nanostructurization (anodization), which was set to be more negative by $5-30 \mathrm{mV}$ from the passivation potential, was applied for $0.5-7 \mathrm{~min}$. The morphology of the anodized surface of the electrode was analyzed by scanning electron microscopy (SEM) using an S-4300 FE-SEM (Hitachi Ltd., Tokyo, Japan). The actual electrode surface area was determined from the reductive charge of gold oxides in the cyclic voltammograms measured in a $0.5 \mathrm{M} \mathrm{H}_{2} \mathrm{SO}_{4}$ solution [46-49]. The roughness factor $\left(R_{\mathrm{f}}\right)$ of prepared NPG was calculated by dividing the electrode surface area by the geometrical surface area of the gold disk electrode. The $R_{\mathrm{f}}$ values of NPG electrodes were arranged by controlling the time for the anodization process.

\subsection{Electrochemical Measurements}

All electrochemical measurements were conducted using an ALS model 660D electrochemical analyzer (CH Instruments Inc., Austin, TX, USA). A normal three-electrode configuration consisting of an $\mathrm{Ag} / \mathrm{AgCl}$ sat. $\mathrm{KCl}$ reference electrode, a Pt auxiliary electrode, and a cleaned commercially available conventional planar-gold or NPG working electrode was employed. Potentials in the results were converted to the reversible hydrogen electrode (RHE) reference [33]. Voltammetry was performed for the potential ranges of -0.3 to $0.5 \mathrm{~V}$, depending on the experimental conditions at potential scan rates of $5-50 \mathrm{mV} \mathrm{s}^{-1}$. 


\subsection{Electrolysis and Product Analysis}

The $\alpha$-keto acids were electrolyzed using the aforementioned three-electrode configuration for 30 and $120 \mathrm{~min}$ at the NPG and conventional planar-gold electrodes, respectively, under a constant applied potential. The Pt auxiliary electrode was separated by ionpermeable porous glass from the working electrode. The electrolyzed solutions, which were expected to have the corresponding L-amino acids, were analyzed by HPLC (Chromaster, Hitachi High-Teck Corp., Tokyo, Japan). The reaction solutions were dried and treated with a PITC solution (the L-amino acids were modified by PITC) according to the manufacturer's instructions. The prelabeled reactants were applied to the Wakosil-PTC column and eluted with a linear gradient from $0 \%$ to $70 \%$ of the aforementioned mobile phase B. The L-amino acids in the electrolyzed solutions were also determined enzymatically with the commercially available colorimetric assay kits following the manufacturers' instructions.

\section{Conclusions}

The anodized NPG surface was employed for the electrochemical molecular conversion of biomass-derivable $\alpha$-keto acids in the presence of a nitrogen source to the corresponding L-amino acids. The surface nanostructurization enabled the reductive amination reaction at a lower overpotential and significantly improved the conversion efficiency. As the applied potential for the electrochemical conversion became more positive, the L-amino acid production efficiency increased. FE values of $89-93 \%$ were obtained for the production of Ala, Asp, Glu, and Leu at the NPG electrode. These were much higher than that $(16 \%$ at maximum) at the conventional planar-gold electrode (without nanostructurization) and close to the highest values ( $99 \%)$ reported for $\mathrm{TiO}_{2}$ electrodes. These results demonstrate that the present facile nanostructurization is effective for improving the reductive amination of $\alpha$-keto acids. They also indicate that it would be useful to develop an electrode catalyst for the electrochemical molecular conversions of redox active species.

Supplementary Materials: The following are available online at https: / www.mdpi.com/article / 10.3390 /ijms22179442/s1, Figure S1: FE for L-glutamic acid production obtained at the NPG electrode as a function of the a-ketoglutaric acid concentration; Figure S2: Scanning electron microscopy images of the NPG electrode before and after the electrolysis experiments.

Author Contributions: Conceptualization, Y.M.; methodology, investigation, Y.M., S.K. and C.M.; data curation, Y.M., S.K. and C.M.; writing-original draft preparation, Y.M.; writing-review and editing, Y.M. and C.M.; visualization, Y.M. and C.M.; supervision, Y.M.; project administration, Y.M.; funding acquisition, Y.M. All authors have read and agreed to the published version of the manuscript.

Funding: This research was partially supported by JSPS KAKENHI, Grant Number JP19K07024, and JFE 21st Century Foundation.

Data Availability Statement: The data presented in this study are available on request from the corresponding author.

Acknowledgments: The authors greatly thank Y. Tamanoue (AIST) for helpful discussions.

Conflicts of Interest: The authors declare no conflict of interest.

\section{References}

1. Wang, F.M.; Li, W.J.; Wang, R.; Guo, T.Q.; Sheng, H.Y.; Fu, H.C.; Stahl, S.S.; Jin, S. Modular Electrochemical Synthesis Using a Redox Reservoir Paired with Independent Half-Reactions. Joule 2021, 5, 149-165. [CrossRef]

2. Tang, C.; Zheng, Y.; Jaroniec, M.; Qiao, S.Z. Electrocatalytic Refinery for Sustainable Production of Fuels and Chemicals. Angew. Chem. Int. Ed. 2021, 60, 2-21. [CrossRef] [PubMed]

3. Akhade, S.A.; Singh, N.; Gutierrez, O.Y.; Lopez-Ruiz, J.; Wang, H.M.; Holladay, J.D.; Liu, Y.; Karkamkar, A.; Weber, R.S.; Padmaperuma, A.B.; et al. Electrocatalytic Hydrogenation of Biomass-Derived Organics: A Review. Chem. Rev. 2020, 120, 11370-11419. [CrossRef] [PubMed]

4. Lam, C.H.; Deng, W.; Lang, L.; Jin, X.; Hu, X.; Wang, Y. Minireview on Bio-Oil Upgrading via Electrocatalytic Hydrogenation: Connecting Biofuel Production with Renewable Power. Energy Fuels 2020, 34, 7915-7928. [CrossRef] 
5. Niwa, O.; Ohta, S.; Takahashi, S.; Zhang, Z.X.; Kamata, T.; Kato, D.; Shiba, S. Hybrid Carbon Film Electrodes for Electroanalysis. Anal. Sci. 2021, 37, 37-47. [CrossRef]

6. Kang, Y.J.; Yang, P.D.; Markovic, N.M.; Stamenkovic, V.R. Shaping electrocatalysis through tailored nanomaterials. Nano Today 2016, 11, 587-600. [CrossRef]

7. Liang, J.; Liu, Q.; Li, T.S.; Luo, Y.L.; Lu, S.Y.; Shi, X.F.; Zhang, F.; Asiri, A.M.; Sun, X.P. Magnetron sputtering enabled sustainable synthesis of nanomaterials for energy electrocatalysis. Green Chem. 2021, 23, 2834-2867. [CrossRef]

8. Biener, J.; Biener, M.M.; Madix, R.J.; Friend, C.M. Nanoporous Gold: Understanding the Origin of the Reactivity of a 21st Century Catalyst Made by Pre-Columbian Technology. Acs Catal. 2015, 5, 6263-6270. [CrossRef]

9. Kim, S.H. Nanoporous gold: Preparation and applications to catalysis and sensors. Curr. Appl. Phys. 2018, 18, 810-818. [CrossRef]

10. Fujita, T.; Guan, P.F.; McKenna, K.; Lang, X.Y.; Hirata, A.; Zhang, L.; Tokunaga, T.; Arai, S.; Yamamoto, Y.; Tanaka, N.; et al. Atomic origins of the high catalytic activity of nanoporous gold. Nat. Mater. 2012, 11, 775-780. [CrossRef]

11. Qiu, H.J.; Xu, H.T.; Liu, L.; Wang, Y. Correlation of the structure and applications of dealloyed nanoporous metals in catalysis and energy conversion/storage. Nanoscale 2015, 7, 386-400. [CrossRef]

12. Bhattarai, J.K.; Neupane, D.; Nepal, B.; Mikhaylov, V.; Demchenko, A.V.; Stine, K.J. Preparation, Modification, Characterization, and Biosensing Application of Nanoporous Gold Using Electrochemical Techniques. Nanomaterials 2018, 8, 171. [CrossRef] [PubMed]

13. Hossain, M.N.; Liu, Z.G.; Wen, J.L.; Chen, A.C. Enhanced catalytic activity of nanoporous Au for the efficient electrochemical reduction of carbon dioxide. Appl. Catal. B 2018, 236, 483-489. [CrossRef]

14. Zeis, R.; Lei, T.; Sieradzki, K.; Snyder, J.; Erlebacher, J. Catalytic reduction of oxygen and hydrogen peroxide by nanoporous gold. J. Catal. 2008, 253, 132-138. [CrossRef]

15. Xia, H.B.; Ran, Y.; Li, H.S.; Tao, X.T.; Wang, D.Y. Freestanding monolayered nanoporous gold films with high electrocatalytic activity via interfacial self-assembly and overgrowth. J. Mater. Chem. A 2013, 1, 4678-4684. [CrossRef]

16. Li, Q.Q.; Cui, S.Z.; Yan, X.L. Electrocatalytic oxidation of glucose on nanoporous gold membranes. J. Solid State Electrochem. 2012, 16, 1099-1104. [CrossRef]

17. Quynh, B.T.P.; Byun, J.Y.; Kim, S.H. Electrochemical Behavior of Aromatic Compounds on Nanoporous Gold Electrode. J. Electrochem. Soc. 2018, 165, B414-B421. [CrossRef]

18. Takale, B.S.; Feng, X.J.; Lu, Y.; Bao, M.; Jin, T.A.; Minato, T.; Yamamoto, Y. Unsupported Nanoporous Gold Catalyst for Chemoselective Hydrogenation Reactions under Low Pressure: Effect of Residual Silver on the Reaction. J. Am. Chem. Soc. 2016, 138, 10356-10364. [CrossRef]

19. Yan, M.; Jin, T.; Ishikawa, Y.; Minato, T.; Fujita, T.; Chen, L.Y.; Bao, M.; Asao, N.; Chen, M.W.; Yamamoto, Y. Nanoporous Gold Catalyst for Highly Selective Semihydrogenation of Alkynes: Remarkable Effect of Amine Additives. J. Am. Chem. Soc. 2012, 134, 17536-17542. [CrossRef]

20. Duan, H.M.; Xu, C.X. Low-temperature CO oxidation over unsupported nanoporous gold catalysts with active or inert oxide residues. J. Catal. 2015, 332, 31-37. [CrossRef]

21. Dononelli, W.; Tomaschun, G.; Kluner, T.; Moskaleva, L.V. Understanding Oxygen Activation on Nanoporous Gold. ACS Catal. 2019, 9, 5204-5216. [CrossRef]

22. Xiao, X.X.; Si, P.C.; Magner, E. An overview of dealloyed nanoporous gold in bioelectrochemistry. Bioelectrochemistry 2016, 109, 117-126. [CrossRef] [PubMed]

23. Wang, Z.L.; Ning, S.C.; Liu, P.; Ding, Y.; Hirata, A.; Fujita, T.; Chen, M.W. Tuning Surface Structure of 3D Nanoporous Gold by Surfactant-Free Electrochemical Potential Cycling. Adv. Mater. 2017, 29, 1703601. [CrossRef]

24. Deng, Y.P.; Huang, W.; Chen, X.; Li, Z.L. Facile fabrication of nanoporous gold film electrodes. Electrochem. Commun. 2008, 10, 810-813. [CrossRef]

25. Kim, M.; Kim, J. Effect of pH on Anodic Formation of Nanoporous Gold Films in Chloride Solutions: Optimization of Anodization for Ultrahigh Porous Structures. Langmuir 2014, 30, 4844-4851. [CrossRef] [PubMed]

26. Nishio, K.; Masuda, H. Anodization of Gold in Oxalate Solution To Form a Nanoporous Black Film. Angew. Chem. Int. Ed. 2011, 50, 1603-1607. [CrossRef]

27. Zhou, C.H.; Xia, Y.; Huang, W.; Li, Z.L. A Rapid Anodic Fabrication of Nanoporous Gold in NH4Cl Solution for Nonenzymatic Glucose Detection. J. Electrochem. Soc. 2014, 161, H802-H808. [CrossRef]

28. Mie, Y.; Ikegami, M.; Komatsu, Y. Nanoporous Structure of Gold Electrode Fabricated by Anodization and Its Efficacy for Direct Electrochemistry of Human Cytochrome P450. Chem. Lett. 2016, 45, 640-642. [CrossRef]

29. Mie, Y.; Takayama, H.; Hirano, Y. Facile control of surface crystallographic orientation of anodized nanoporous gold catalyst and its application for highly efficient hydrogen evolution reaction. J. Catal. 2020, 389, 476-482. [CrossRef]

30. Sukeri, A.; Saravia, L.P.H.; Bertotti, M. A facile electrochemical approach to fabricate a nanoporous gold film electrode and its electrocatalytic activity towards dissolved oxygen reduction. Phys. Chem. Chem. Phys. 2015, 17, 28510-28514. [CrossRef]

31. Kim, J.; Song, J.T.; Ryoo, H.; Kim, J.G.; Chung, S.Y.; Oh, J. Morphology-controlled Au nanostructures for efficient and selective electrochemical $\mathrm{CO}_{2}$ reduction. J. Mater. Chem. A 2018, 6, 5119-5128. [CrossRef]

32. Mie, Y.; Katagai, S.; Ikegami, M. Electrochemical Oxidation of Monosaccharides at Nanoporous Gold with Controlled Atomic Surface Orientation and Non-Enzymatic Galactose Sensing. Sensors 2020, 20, 5632. [CrossRef] 
33. Fukushima, T.; Yamauchi, M. Electrosynthesis of amino acids from biomass-derivable acids on titanium dioxide. Chem. Commun. 2019, 55, 14721-14724. [CrossRef]

34. Besson, M.; Gallezot, P.; Pinel, C. Conversion of Biomass into Chemicals over Metal Catalysts. Chem. Rev. 2014, 114, 1827-1870.

35. Zhou, C.H.; Xia, X.; Lin, C.X.; Tong, D.S.; Beltramini, J. Catalytic conversion of lignocellulosic biomass to fine chemicals and fuels. Chem. Soc. Rev. 2011, 40, 5588-5617. [CrossRef]

36. Ogo, S.; Uehara, K.; Abura, T.; Fukuzumi, S. pH-dependent chemoselective synthesis of alpha-amino acids. Reductive amination of alpha-keto acids with ammonia catalyzed by acid-stable iridium hydride complexes in water. J. Am. Chem. Soc. 2004, 126, 3020-3021.

37. D'Este, M.; Alvarado-Morales, M.; Angelidaki, I. Amino acids production focusing on fermentation technologies-A review. Biotechnol. Adv. 2018, 36, 14-25. [CrossRef] [PubMed]

38. Wang, J.; Liu, X.H.; Feng, X.M. Asymmetric Strecker Reactions. Chem. Rev. 2011, 111, 6947-6983. [CrossRef] [PubMed]

39. Jeffery, E.A.; Johansen, O.; Meisters, A. Electrochemical synthesis of amino-acids by reductive amination of keto ACIDS.2. reduction at platinum black and palladium black electrodes. Aust. J. Chem. 1978, 31, 79-84. [CrossRef]

40. Anne, A.; Daninos, S.; Moiroux, J.; Bourdillon, C. Electrochemical reduction of alpha-ketoglutarate in the presence of ammonia as a means of achieving selectively the reductive amination to glutamate-Thermodynamic and kinetic characteristics of the keto imine equilibrium. New J. Chem. 1994, 18, 1169-1174.

41. Markle, W.; Lutz, S. Electroenzymatic strategies for deracemization, stereoinversion and asymmetric synthesis of amino acids. Electrochim. Acta 2008, 53, 3175-3180. [CrossRef]

42. Chen, L.Y.; Lang, X.Y.; Fujita, T.; Chen, M.W. Nanoporous gold for enzyme-free electrochemical glucose sensors. Scripta Mater. 2011, 65, 17-20. [CrossRef]

43. Xiao, X.X.; Ulstrup, J.; Li, H.; Wang, M.E.; Zhang, J.D.; Si, P.C. Nanoporous gold assembly of glucose oxidase for electrochemical biosensing. Electrochim. Acta 2014, 130, 559-567. [CrossRef]

44. Ruffino, F.; Grimaldi, M.G. Nanoporous Gold-Based Sensing. Coatings 2020, 10, 899. [CrossRef]

45. Norskov, J.K.; Bligaard, T.; Logadottir, A.; Kitchin, J.R.; Chen, J.G.; Pandelov, S.; Norskov, J.K. Trends in the exchange current for hydrogen evolution. J. Electrochem. Soc. 2005, 152, J23-J26. [CrossRef]

46. Wang, Y.; Sun, Y.M.; Liao, H.B.; Sun, S.N.; Li, S.Z.; Ager, J.W.; Xu, Z.C.J. Activation Effect of Electrochemical Cycling on Gold Nanoparticles towards the Hydrogen Evolution Reaction in Sulfuric Acid. Electrochim. Acta 2016, 209, 440-447. [CrossRef]

47. Sukeri, A.; Bertotti, M. Nanoporous Gold Surface: An Efficient Platform for Hydrogen Evolution Reaction at Very Low Overpotential. J. Braz. Chem. Soc. 2018, 29, 226-231. [CrossRef]

48. Sadakiyo, M.; Hata, S.; Fukushima, T.; Juhasz, G.; Yamauchi, M. Electrochemical hydrogenation of non-aromatic carboxylic acid derivatives as a sustainable synthesis process: From catalyst design to device construction. Phys. Chem. Chem. Phys. 2019, 21, 5882-5889. [CrossRef] [PubMed]

49. Lukaszewski, M.; Soszko, M.; Czerwinski, A. Electrochemical Methods of Real Surface Area Determination of Noble Metal Electrodes-An Overview. Int. J. Electrochem. Sci. 2016, 11, 4442-4469. [CrossRef] 